\title{
Keep fit: Marginal ideas in contemporary therapeutic exercise
}

Exercise has a long history as a therapeutic modality and has existed, in some form, in all cultures throughout recorded history. In recent years, therapeutic exercise has taken on new significance as a relatively low cost medical intervention designed to improve people's health and wellbeing and reduce the downstream effects of comorbidity. Drawing our inspiration from Foucault and Deleuze, we argue that seeing therapeutic exercise as primarily 'medical' carries with it consequences - some recognised, others unseen - that are problematic and worthy of consideration. Our focus is on the acts of marginalisation, exile and exclusion implicit in the quotidian practice of therapeutic exercise, and how these acts mediate people's daily lives. In the paper we explore how therapeutic exercise is being instrumentalised, normalised and constrained, arguing for much greater critical attention towards its putative 'goodness' and virtue as a health intervention.

Keywords: therapeutic exercise; play; Foucault; Deleuze

\section{Introduction}

Exercise has been used therapeutically for as long as civilisations have recorded their activities. Frank Krusen, the eminent historian of physical medicine, wrote in 1942 that Herodikus of Selymbria in the $5^{\text {th }}$ century BCE 'attributed all diseases to errors in diet and exercise', prescribing 'special foods, exercise, particularly walking and bathing', as forms of medicine (Krusen 1942, 13), and Krusen believed that 'there are books as old as five thousand years written about gymnastics' (ibid). Historically, exercise has been closely aligned with medicine and has been distinguishable from other forms of physical activity by its teleological, therapeutic and prescriptive purpose. Frederic Kottke's classic definition of therapeutic exercise states that it involves 'the prescription of bodily movement to correct an impairment, improve musculoskeletal function or maintain a state of wellbeing' (Kottke 1965, 365). There is some evidence then to demonstrate that therapeutic exercise has been coterminous with treatment, 
rehabilitation and recovery, and is a form of exertion, effort and work in the service of restoration of putatively normal bodily functions. Therapeutic exercise is distinguishable from other forms of recreation because it is a purposeful, body-building activity, often prescribed by experts (Wheatley 2005), drawing on their knowledge of bodily function to engage in a powerful form of anatomo-politics (Foucault 1977). ${ }^{1}$ So if therapeutic exercise has such a long and familiar history, and is so clearly an established form of medicine, why are we - as authors of this paper and researchers in this field - provoked to question its use and utility today? What contemporary ruptures would prompt us to explore what is being gained and what may be being lost in present deployments of therapeutic exercise?

The answer lies partly at the intersection of biopolitical, critical, cultural, material practices, along with economic and social discourses that have brought exercise once more to prominence as a strategy for social welfare. There have been many times in the past when people have turned to therapeutic exercise as a significant medicine-led intervention targeted at improving the health and wellbeing of all, such as the introduction of military 'drilling' into schools in the early 1900s (Armstrong 2002); the physical culture movement of the inter-war years (Zweiniger-Bargielowska 2006); and the fitness industry boom of the 1980s (McKenzie 2013). So what is it about the current episteme that invites and incites us to reconsider this practice? Health sociologists, historians and others have argued for a long time that therapeutic exercise can reveal much about shifting attitudes towards bodies, productivity and leisure, and

\footnotetext{
${ }^{1}$ Foucault described anatomo-politics as a process by which the body is disciplined to optimise its capabilities, so that it can be integrated into a wider governmental system of efficiencies and controls. Here the body becomes useful and docile and the object of biopower (Foucault 1990, 139).
} 
that it has exceptional adaptability and plasticity as a disciplinary technology (Pronger 1995). In recent years, therapeutic exercise has demonstrated a remarkable facility to function as a form of individualising and responsibilising agency, which has been pivotal to the operationalisation of neoliberal economic and social reforms, whilst also retaining its relevance for experts and professionals as a form of justified individual and collective intervention (Rose 1999, 2001). But what is particular, for us as an interdisciplinary group of scholars writing together here, about this moment?

To address this question, we have interrogated a range of discourses and practices that are frequently silenced, marginalised, or otherwise excepted from mainstream conversations and enactments around the virtues of therapeutic exercise. In a field dominated by bioscientific and positivist epistemologies, we seek to contribute to 'the notion that continuous questioning, rethinking and potentially revisioning of our epistemological and ontological orientations can be productive for pushing inquiry forward' in the field of exercise and health (Giardina 2017, 260). Our collaborative project was created to interrogate the bioscientific framing of exercise as medicine, drawing particularly on the writings of Michel Foucault and Gilles Deleuze.

The central focus for this paper is the argument that activity has been medicalised through a strategy of capture embodied by the event known as 'therapeutic exercise'. Therapeutic exercise assumes a number of things about activity: that it is amenable to instrumentalisation, regulation and control; that it is qualitatively different to free, pleasurable, pointless activity and play; and that the widespread use of measurement and surveillance of activity is necessary given our contemporary anxieties about the downstream effects of indolence and passivity. Our argument is that these discourse are problematic and worthy of critical scrutiny. 
We approach this question through a variety of problem spaces and tensions surrounding contemporary therapeutic exercise. Our philosophical and substantive focus is plural, reflecting both our different theoretical interests, but also a plurality of critical positions that can be taken towards that which is 'othered' when exercise is seen as medicine. We examine the present obsessions with physical (in)activity and unhealthy lifestyles; the effects of technologically-mediated self-surveillance on personal conduct; paradoxical relationships with rest and idleness; and enduring healthism. The critique we offer in this paper troubles the practice of therapeutic exercise, and in so doing highlights a pernicious and problematic way in which exercise has been colonised as a medical discourse. We argue that when we claim that exercise is medicine, we can, at times, marginalise a number of other possible meanings (exercise as leisure, exercise as social connection, exercise as aesthetic creation, etc.), and other options for healing (convalescence as medicine, passive treatments as medicine, hedonism as medicine, etc.). Recognising these discursive borders and material practices, we ask what this doing does, and what a more permeable and flexible interpretation and practice of therapeutic exercise and medicine might make possible.

\section{The normalisation of bio-pedagogies}

Exercise as an intervention has been wholly taken up by kinesiology, human kinetics, and physical education faculties in recent years. The discourse and practice of exercise as an intervention confirms the epistemological hierarchies and triumphant hegemony of positivistic, evidence-based biomedical sciences (Andrews, 2008). In such environments, pragmatic education, technocratic knowledge and a 'technological habitus' (Pronger 1995) may become pervasive, resulting in the marshalling of bodies as resources for the virtuous interventions of therapeutic exercise experts (Wheatley 2005). K. Gibson (2015b, 2016) argues that many new studies in public health, 
medicine and kinesiology extol the virtues of exercise as a means addressing illness. Indeed, many of the beliefs about therapeutic exercise as medicine have influenced kinesiology and human kinetics curricula and programs, their research and funding, and their outreach (Andrews, 2008; K. Gibson, 2016). One kinesiology faculty's recent titles for their public symposia -'Extreme environments, extraordinary feats: 'How far can we push ourselves?'; and 'What happened to walking?' - demonstrate the importance of communicating the 'exercise as medicine' concept to the general population. These moves by kinesiology faculties signal the pervasive 'self-legitimizing hegemony of evidenced-based natural-science' (Andrews 2008, 49). It is difficult to ignore these paradigms, promoted by kinesiology and exercise science researchers, because they have been deployed to; keep the middle classes fit and well, through constant work on the body, while quantifying the self through the keeping of dataveillance (Rail, 2012); regulate the labouring bodies of marginalised workers producing commodities (fitbits, clothing, shoes (****2012); proliferate wellness campaigns to turn people towards exercising and away from sedentariness and obesity. With a focus on increasing rates of obesity among children, children's physical activity, health and well-being is increasingly being scientifically scrutinized in an effort to ensure children live physically active and productive lives.

As the number of overweight children around the world eclipsed 42 million in 2015, childhood obesity has been identified as one of the most serious public health challenges of modernity (World Health Organization 2017). With mounting moral panic surrounding this purported epidemic (Evans, Rich, Davies and Allwood 2008), therapeutic exercise has been promulgated as a critically important strategy and a potential panacea in the fight against this burgeoning worldwide phenomenon (World Health Organization 2017). Advocates ostensibly argue that therapeutic exercise has the 
potential to mitigate the risk of developing diabetes, cardiovascular disease, and a range of metabolic disorders; whilst also enhancing mental health, and reducing obesity itself (Carson et al. 2013; Carson et al. 2014; Lees and Hopkins 2013; World Health Organization 2017). In the wake of these weight-related concerns, we have seen a proliferation of interventionist strategies that have been designed to motivate, regulate and stimulate therapeutic exercise in children and youth. Dovetailing with a discourse that has been promoted since at least the Industrial Revolution (Foucault, 1990), children have been, and continue to be, repeatedly encouraged to 'develop an understanding of what they need in order to make a commitment to lifelong health, activity living, and develop the capacity to live satisfying, productive lives' (Ontario Ministry of Education 2015, 7). History has shown us that targeted interventions including activity- and play-based curricula reforms (**** 2016) - are being designed to mitigate the symptoms of common health problems (Lang et al. 2010), and to target children's attitudes and behaviours (Armstrong 2002). To do so, therapeutic exercise has made an incursion into children's play in an effort to purportedly enhance children's development, health and well-being.

Indeed, for children, (lack of) exercise and, in more recent years, play, has come under intense scrutiny (**** 2015). Play has been reported as 'extinct', 'not active enough', 'not useful' and 'less risky than in the past' (see AHKC 2012; ParticiPACtion 2016). Public health agendas have zeroed in on play because 'children do not come out to play anymore' (Powell 2013) and have recommended that we 'bring back play' (see AHKC 2012; ParticiPACtion 2016). Not unstructured, free and frivolous play, however, but physically active play - 60-minutes/day - which aligns with utilitarian, biopedagogical and future-orientated medicinal therapeutic exercise $(* * * * 2014$; **** 2015; Frohlich et al. 2012; **** 2016). In neoliberal times, there is a preoccupation 
with bodies, and health and lifestyle are perceived as solutions to the fiscal crisis of the welfare state (Ingham 1985). As such, the shock doctrines (Klein 2007) of technomedicine and biocapitalism (Rose 2007) appear to offer restorative therapeutic exercise to children (and their parents), through individualised, family-orientated activities. These seek to cultivate dutiful, governable, and normative subjects (Miller and Rose 2008); 'not for the sake of punishing them but for the sake of rescuing, rehabilitating, and saving them' (Rail 2012, 241), from a future life of ill health and disease.

Yet, notwithstanding the rationale for these interventions, the act of instrumentalising physical activity can have multiple (unintended) effects; effects that are seldom discussed in the academic literature. Our contention is that some of the broader effects of instrumentalising children's activity directly impact on the wellbeing of the children themselves. For example, as children's unstructured activity is increasingly controlled by movement experts like epidemiologists, exercise physiologists, kinesiologists and physiotherapists, under whose care the emphasis shifts from creative learning, fun and participation, towards a more utilitarian notion of regulated therapeutic exercise as a preventative and outcomedriven health strategy (K. Gibson 2015a, 2016). Such a focus reifies, (re)shapes, and (re)produces physical activity as a goal-oriented activity, designed to prevent, manage, and intervene in the governance of children's health. By predominantly instrumentalising physical activity in these ways, exercise becomes medicine, which de-emphasises the pleasure, freedom, creativity, spontaneity, adventure, and risk associated with unregulated activity. In an environment where play and physical activity are becoming biomedicalized, rather than an end in and of themselves (****2012), exercise supplants free expression, and the cultural, 
pleasurable, embodied, emotional, physical, relational, and social dimensions of movement.

There has been a sustained critique of the so-called 'obesity epidemic' and the institutionalisation of bio-pedagogies especially, but not exclusively, for children in global north societies of Australasia, Europe and North America (Gard and Wright 2005; Rail 2012; Rich 2011; Wright and Harwood 2009; **** 2017). The proliferation of programs to get children moving, for example, aligns with the 'normalised scientism evident in the kinesiology community' (Andrews 2008, 49), and through these programs normative inscriptions and prescriptions (what bodies should look and exercise like, where they should exercise, etc.), are (re)produced and (re)calibrated. Pronger (1999) and Sothern (2007) might argue that therapeutic exercise is a libidinal economy that seeks the cultivation of a stable, unified sovereign identity/subject, that is phallocentric and protective of the space and health of the self - with the disciplined, hard(ened), (often) heteronormative, (often) masculinised body acting as the absent referent to which all other bodies are measured. In this context, jiggly flesh, belonging to nonphallocentric subjects, is rendered obscene and ugly because it gives flesh to the body's malleability, through which a lack of sovereignty is indicated when it is prodded or even when it moves (Pronger 2002, 235).

If normativity is found to be implicit when exercise is medicine, then this 'constitutes a discourse on the body that seeks to foreclose its potential' and, while purporting to offer salvation from illness and disease, 'a modern technological approach to the body articulates a will to domination that is ultimately fascist' (Pronger 2002, 10, 23). In such instances, the subject of therapeutic exercise becomes intelligible only through its orientation towards the 'straight line' of exercise. This line, according to 
Ahmed (2006), 'makes certain things, and not others, available' (14) and 'for a life to count as a good life' means 'it must return the debt of its life by taking on the direction promised as a social good, which means imagining one's futurity in terms of reaching certain points along the life course' (21). Therapeutic exercise 'shapes bodies by what is and is not brought near to them' (54); it 'orients bodies in some ways rather than others' (57). While straightness marks the exercising body, those disciplines that have much to gain from 'exercise is medicine' discourses and practices (kinesiology, physical education, and physiotherapists, for example), also continue to reproduce hegemonic cultures in which whiteness and Eurocentrism remain the invisible norms (Douglas and Halas 2013). This euro-domination may have implications for both localized and globalized bodies, as the scientific premises and global health movements that emerge from these disciplinary areas often, for example, undergird the organizing principles for, the Sport for Development movement (Darnell, 2014) or the international consortium that have joined together to address and release report cards on children's physical (in)activity (Activity Health Kids Global Alliance, 2017). The influence of the normalising and colonial discourses and practices that have been so important in the historical cultivation of the (white) bourgeois national citizen-subject (Stoler, 1997) of exercise sciences and physical education (Douglas and Halas 2013), must be taken into account in this exercise as medicine era.

In his interrogation of the technologies of physical fitness, Pronger (2002) concludes that 'seemingly innocuous, indeed well-intentioned systems do violence, both symbolically and 'materially,' to our potential for living full lives' (12). Cornell 1992) asks: 'Who or what is left outside these kinds of (exercise) systems?' In the therapeutic exercise paradigm, the precarity and vulnerability of other(ed) bodies (LGBTQI, fat, disabled, poor, racialised), may be rendered abject, illustrating 'a phobic majoritarian 
public sphere that continuously elides or punishes the existence of subjects who do not conform to the phantasm of normative citizenship' (Muñoz 1999, 4); a phobic majority who may be disgusted by, and heap shame onto, the non-normative body (Probyn 2000).

While it may not be possible to avoid the calls to view exercise as medicine (K. Gibson, 2015b; 2016), it may be possible to subvert such calls through a queer antiracist critique (Douglas, Jivraj and Lamble 2011) that might advocate for a 'disidentification' (Muñoz 1999) with, and a disorientation (Ahmed 2006) from, the pervasive inscriptions and prescriptions that are premised on the white-settler colonialist discourses and practices kinesiology and exercise sciences (Douglas and Halas 2013). Such refusals can help to reveal what is lost by following the 'straight(ened)' line and/or abjecting jiggly flesh which 'has a life of its own, oblivious to the will of the sovereign subject', and what might be gained through an engagement with an alterity that 'lies in the open, flabby, impermanent body that the technology of physical fitness tries so hard to exclude' (Pronger 2002, 235).

\section{The grim spectacle of the gymnasium}

The recent proliferation of advice on therapeutic exercise and activity resonates with claims that sedentary behaviour is 'the new smoking' (see, for example, http://www.thisislondonwellness.com/wellness-journal/is-sitting-the-new-smoking), and that a new generation are at risk of serious downstream illness because of their preference for video games over 'real' play (Brady, Lowe and Lauritzen, 2015). These discursive practices tap into widespread anxieties about present and future health, in part because they come at a time when there are real concerns about the rising cost of formal health care (Azguridienè and Delkeskamp-Hayes 2015; Mingardi 2015). Following Rose Galvin's questioning of the rapid growth of health promotion, there is a 
sense that people's 'culpability in the face of known risk' (Galvin 2002) has now penetrated deeply into every moment of our waking lives, such that every figurative and metaphorical step is now amenable to monitoring and control.

Galvin's argument echoes Foucault's assertion that it is the most taken-forgranted and obvious everyday actions that are the most interesting, and the ones that we should all scrutinise most carefully, because it is in these actions that the most efficient relations of power operate (Foucault 1977). Given this, the speed with which people have embraced calls for populations including families, children and youth to be concerned about their levels of activity (Dagkas \& Burrows, 2016; Rail, 2012; Wright \& Harwood, 2009), demands attention. This problematisation does not, of course, begin from the standpoint that the growing attention given to everyday activity, exercise as self-care, or physical therapies, is necessarily bad, only that it is dangerous to assume that it is unquestioningly good, or that it is not without its complexities and thereby unworthy of scrutiny. For example, one array of discourses that appear to have been marginalised in much of the recent discussion about the value of therapeutic exercise and activity monitoring is the value of rest and repose, convalescence and the indulgent pleasures of idleness. This is of importance, in part, because activities associated with convalescence, relaxation and repose (health tourism, recuperating after surgery, 'taking the waters', and holidaying in the mountains, for example), have been features of formal health care, as well as desirable characteristics of non-industrial cultures, for millennia (Lupton 2012). Why, then, has this recent interest in the constant monitoring of activity, and these anxieties about sedentary behaviour, become so prevalent? Why this, why now?

Mark Greif recently wrote that '[w]ere 'In the Penal Colony' to be written today, Kafka could only be speaking of an exercise machine' (Greif 2016, 3). Greif argued that 
a self-disciplining gymnasium culture has been built in the image of the leftover machinery of the factory, and turned physical activity into a grim social spectacle in which, like the elevator 'you are expected to face forward' (Ibid, 5). The anxious freedom that comes with constant counting and self-monitoring has become a pervasive feature of modern exercise culture, with technology-assisted measurement on hand to provide real-time feedback on every step, video-assisted performance monitoring, and social media sharing of those moments when we have bested ourselves. And all this, Greif argues, because just over the near horizon sits the spectre of unforeseen illness, injury and death, and so we are now encouraged to take control of any aspect of our lives that might reduce the risks of premature morbidity and mortality, while other aspects of lived health are pushed to the sidelines. Whereas once people living in developed economies benefitted from state-based support when they became ill and subject to what Talcott Parsons famously called the 'sick role' (Parsons 1951), or entered what Susan Sontag called that 'other place' of illness and suffering (Sontag 1977, 3), many countries are now experiencing rapidly contracting centralised public health services, and this is accelerating the need for citizens to look after themselves, because in the future, no-one else will. Echoing Robert Crawford's healthism (Crawford, 1980), Greif argues that, 'The person who does not exercise...is a slow suicide. He (sic) fails to take responsibility for his life. He doesn't labour strenuously to forestall his death. Therefore we begin to think he causes it' (Greif 2016, 6).

These are, of course, not new concerns, having been a feature of contemporary Western culture since the age of the Industrial Revolution (see, for example, Zander's therapeutic exercise machines of the late 19th century (Terlouw 2007)), and desires to harness the productive capacities of the body have established a schizophrenic dromological culture that craves rest yet sees inactivity as pathological (Virilio and 
Polizzotti 1986). In this context, therapeutic exercise functions as a disciplinary technology par excellence (Foucault 1977). It costs virtually nothing, is available to everyone, it engenders personal responsibility, and maximises time and labour (McKinlay and Taylor 2014; Foucault 1977, 164). But what has been lost in this unrelenting quest to ward off illness, suffering or a premature death, and our desire to sculpt bodies and optimise physical functioning?

It might have been naïve to think the new human freedom would push us toward a society of public pursuits, like Periclean Athens or of simple delight in what exists, as in Eden. But the true payoff of a society that chooses to make private freedoms and private leisure its main substance has been much more unexpected. This payoff is a set of forms of bodily self-regulation that drag the last vestiges of biological life into the light of a social attraction (Greif 2016, 5).

It could be argued that the dividend of nearly four centuries of wealth and civilisation has not been spent on authentic cultural aesthetic engagement: freedom from toil, and collective social and cultural growth. Instead it has brought us anxiety, hypervigilence, and a machinic vanity directed at forestalling our inevitable decline.

Coercive power, however, always carries with it the possibility for resistance, and the micro-fascisms of therapeutic exercise (Pronger 2002), and constant selfsurveillance belie an enduring desire for mindfulness, relaxation, rest and repose. At the same time as we experience the pressures of unrelenting labour, we are more disposed to ensure we take 'time out', manage our stresses, enjoy good sleep and the company of friends, travel for refreshment, read for pleasure, become leisure-able.

\section{Desiring exercise}

By contrast with the kinds of Foucauldian biopolitical and biopedagical critiques we have applied to contemporary notions of therapeutic exercise thus far, Deleuze's ontology of affect and desire offers some new and enchanting ways to understand the play of bodily capabilities that constitute therapeutic exercise assemblages. 
Extending this notion of liberation and ecstasis, Deleuze and Guattari's notion of desire functions as a radical departure from the reductive bio-centrism of a culture in which exercise is often seen as medicine. Desire, as Deleuze and Guattari see it, can be thought of as freedom to: freedom to experiment with the body, how it moves and attaches itself to other bodies, things, ideas, expressions, and affects. Eschewing the notion of a fixed subject contained within a physical body, Deleuze and Guattari (1983, 1987), like other postmodern scholars, suggest subjectivities are distributive, both confined to individual bodies and simultaneously connected via constant states of flux. They posit that Western notions of the individuated subject limit desire, that is, flows and possibilities for making and breaking connections. In their formulation, desire is not related to 'wanting'. There is no purpose, endpoint, or goal in desire other than experimentation. A want, they suggest, is a compulsion to address some kind of perceived lack. Instead, productive desire is a passion-in-motion that connects elements together in creative combinations, resisting forces which conspire to maintain the status quo. Deleuze and Guatarri suggest, 'It is ... the subject that is missing in desire or desire that lacks a fixed subject; there is no fixed subject unless there is repression' $(1983,26)$. This notion of free-flowing desire can be mobilised to examine exercise within and beyond medicine.

Desire helps to wrest exercise from the endpoints of medicine and the narrow goals of health. Deleuze suggests that Western thought is preoccupied with what something is or is not. He posits instead a (never completed) exploration of 'and'. 'And' he notes 'is neither one thing nor the other, it is always between two things' (Deleuze 1995). So we might ask, what else is exercise, what else can it do? Exercise produces sensations; it moves people physically and affectively (e/motion); it allows people to re/create (recreation); and it can also hurt, harm, even kill. Exercise does many things. It 
does medicine and it does pleasure and it does them sometimes at the same time, and not at all at other times. It is many things all at once and never stable. Desire signals a never-ending state of becoming, an open system of assemblages that are continually reconfigured.

The distinction between 'wanting', a force driven by negative differences, and desire which is driven by positive relations (Taguchi and Palmer 2014), suggests the limitations and dangers of claiming that exercise is medicine. Medical goals that attempt to address a perceived lack or risk can impose anxiety, shame, guilt, and other forms of social and existential suffering. Take, for example, the prescription of a disabled child's therapeutic home exercise program. In medical rehabilitation contexts, exercise is employed towards realizing particular medical outcomes wherein professionals prescribe and deliver home exercises designed to stretch, strengthen, and reshape bodies to approximate 'normal' aesthetics and movements (Damiano 2006). Professional interventions construct a problem to be rectified (a physical impairment) and envision a future endpoint of resolution (normalisation). In an effort to secure children's sustained cooperation, efforts are made to address therapeutic goals through 'fun' activities like team sports, swimming, or computer-mediated physical activity. These efforts may be helpful in many ways but, as stated earlier, they can have multiple effects beyond the intended outcomes. Children - as biologically-constructed individuated entities - learn that their different ways of moving are under constant scrutiny and in need of correction. Home exercises may be dull and repetitive, and play is co-opted to achieve other goals. Disabled children are aware of these efforts and learn that their bodies are problems to be solved rather than a source of pleasure (****2016). By contrast, Deleuze offers the image of a Body-without-Organs ( $\mathrm{BwO})$ : not merely the biological body deployed when exercise is medicine, but a body that is irreducible to medicine and 
science, passions and actions (Deleuze 1988). The BwO cannot be defined by body systems, functional capacities, or singular identities, but by motion and rest, and through its ability to affect and be affected by other entities (ibid).

We might contend, therefore, that where Foucault provides us with tools to better understand how therapeutic exercise may be captured by a series of biopolitical and biopedagogical strategies, designed to 'fix' the subject within a web of micropolitical rationalities that privilege the kinds of technologies of discipline favoured by health 'practitioners', Deleuze and Guattari offer us escape paths and new lines of flight. Through the $\mathrm{BwO}$ and notions of affect, Deleuze and Guattari talk of 'man's nonhuman becoming', as a 'zone of indetermination, of indiscernibility' (Deleuze \& Guattari 1994, 173), and 'an ontology of flows and becoming which does not distinguish between base and superstructure' (Garo 2008, 56).

For Deleuze and Guattari affect carries with it the possibility of undermining authoritarianism (through language), and the development of unexpected social-cultural relationships (Cole 2009, 2). In the latter case, Deleuze and Guattari explore the hylomorphic possibilities of power arising organically from within systems rather than being imposed from without; what Deleuze and Guattari's called 'machinic phylum' (DeLanda 1997). In many ways this is the message of their work Anti-Oedipus - that true desire is castrated by the "various mechanisms that sustain a human actuality or anti-creativity' (Hallward 2006, 69).

Deleuze and Guattari's writings speak to the irrepressible 'conatus' (Bennett 2009) of activity and movement, and the tendency for 'therapeutic' exercise to constrain free expression rather than enable it. The therapeutic encounter is a 'desiring machine' that cannot be exhausted by the kinds of biopolitical and biopedagogical strategies being deployed by health and exercise professionals. As Williams argues, 'Bodies, in 
short, from their leaky fluids to their overflowing desires and voracious appetites, are first and foremost transgressive: demonstrating their continual resilience to rational control' (Williams 1998, 438).

Deleuze and Guattari's work, therefore leads us away from the technologies of capture that characterise contemporary biopedagogies and disciplinary regimes, where therapeutic exercise marginalises, exiles and excludes some ways of becoming in the name of medicine. Deleuze and Guattari's notions of affect and desire may offer some particularly enchanting opportunities for new approaches that flow and flee; that escape[s] the binary organizations, the resonance apparatus[es], and the overcoding machine[s]' (Deleuze \& Guattari 1987, 238) that currently governs the discourses of therapeutic exercise.

\section{Discussion:}

There is little doubt that therapeutic exercise serves many useful and important functions in people's lives. Evidence suggests that therapeutic exercise can significantly improve people's level of function, levels of pain and quality of life (Fletcher et al 2013), and serves as an important strategy in the management of many impairments, disabling conditions and morbidities. Therapeutic exercise can also be problematic however, especially when its virtues are assumed to be obvious, its shortcomings are minimised or ignored, or an over attention to it detracts from other important elements of living well. We have attempted in this paper to examine some of the troublesome aspects of therapeutic exercise, and deployed a range of theoretical and philosophical positions to highlight the breadth of critique available. This is not, of course, to suggest that all therapeutic exercise is bad, only that in promoting some important uses, other effects and possibilities are marginalised, lost or remain unstated. The question we are attempting to pose in the paper, therefore, is how does an analysis 
of some of the largely silenced aspects of the medical deployment of therapeutic exercise reveal some of the prevailing discourses and practices surrounding activity, play, rehabilitation and health in general?

Our analysis focuses largely on a range of neoliberal economic and political influences on healthcare, and how therapeutic exercise has been mobilised as a medical intervention in support of a range of contemporary discourses. These include:

- Consideration of the ethical implications of what is excluded when exercise is conceived of, and practiced, as medicine and the potential unintended outcomes of this.

- The capturing and formalisation of 'activity' to inculcate appropriate attitudes towards free expression and play, without force or overt expressions of discipline, in order that the people develop suitable lifelong habits;

- The necessity to take care of oneself through a series of daily bodily practices, to ward off the deleterious effects of ageing and bodily decline;

- The containment of desire and the restatement of goals, objectives and teleological purposes for the expenditure of surplus human energy;

- The commodification of activity such that all forms of therapeutic exercise become associated with the consumption and reproduction of an unobtainably optimised series of body-projects.

Prevailing discourses of therapeutic exercise available in the kinds of scientific

literature promoted to practitioners, largely ignore these critiques, encouraging, instead, an overly quantifiable, reductive, biomedical, aetiological and teleological view. Such dominant discourses conceal certain kinds of dogma, tradition, and practices of marginalisation that serve to retain and restate the influence of these competing epistemologies. But it is perfectly possible to use a range of theoretical and philosophical approaches, as we have sought to do here, to read through these discourses and expose them to a degree of critical scrutiny. The goal of such a critique is not to propose the singular solution to the problems posed by our analyses, but to open a door to a thousand alternatives, each of which then would become the subject of further critical analysis.

In the context of this paper, the attention given to the way activity, exercise and play have been instrumentalised and mobilised as a technology of discipline, builds on work 
conducted into the political history of exercise (Armstrong 2002, Till 2014), critical analyses of rehabilitation, and the biopolitics of conduct (***2016, ***2017). What these various studies reveal is that the clear linkage between activity and the broader economic and political goals has, for many years, created possibilities for therapeutic exercise to be used as a technology of capture in the mobilisation of productive, significant and purposeful activity, exercise and play. Thus, the regular measurement of people's performance against putative developmental and productivity norms; the use of evidence-based calls for more physical activity; and other such disciplinary technologies, have now been supplemented by newer, technologically-enabled mechanisms of coercion. Most notably, these include digital surveillance devices and public health supported tests and measures that, superficially support people to be fit, but anticipates, more significantly, offer a future in which we will all be required to take more personal responsibility for supporting ourselves as we age.

Our examination of these technologies poses questions about the way therapeutic exercise is serving as a form of medical intervention. But we are equally interested in the ways medicine is being mobilised in yet more ways to legitimise and justify interventions at individual, community and broader social levels: technologies that enhance both the significance of therapeutic exercise as a low-cost, autonomyenhancing intervention, and the status of the practitioners who dispense these modalities. Therapeutic exercise is, in many ways, an archetypical biopolitical technology: it is highly adaptable to context; disinterested and agnostic towards aptitude, culture, values and beliefs; low cost, requiring only that the person or group make good use of their local environment; open to expert specialisation and the development of bespoke services and deliverables; and scalable between individualised conduct and population-wide interventions. 
Therapeutic exercise's future as a health promotion strategy par excellence would also seem to be secure, with most authorities arguing that activity underpins most, of the causes of future poor health in the developed world (Fletcher et al 2013). Its potential as a vehicle for future bodily pedagogies and practices of consumption associated with the search for optimal bodily comportment, beauty, health and wellbeing, is bringing therapeutic exercise increasingly into line with transcendental questions about the possible futures for bodies that are now amenable to prosthetic enhancement, delayed obsolescence and sustained productivity. All that is required is that the person, group or community make a concerted, habitual and lifelong commitment to maintain their bodyas-machine until the point comes when more radical adaptations become available.

Health professionals, exercise and rehabilitation practitioners are all important for this process of 'behaviour change'. They have benefitted - and continue to benefit - from their relatively uncritical promotion of the kinds of neoliberal biopolitics we explore in this paper. The responsibility is greater for these people, perhaps, to take a critical stand against the seemingly mundane, quotidian, and obvious benefits of therapeutic exercise, and to ask whose interests are being served, and whose are being marginalised; which discourses are making some things possible, and what is being denied? Armed with this more critical stance, we have advocated for Deleuze and Guattari's approaches to the Body without Organs, affect, desire and lines of flight as tools to engage with a more immanent, less reductive, more nuanced approach to therapeutic exercise. Such an approach would embrace exercise as medicine, but would also see the value in exercise as expression and indulgence, luxury and creativity, as well as giving therapeutic value to such notions as rest, repose and indolence.

\section{Acknowledgements}

None. 


\section{References}

AHKC (Active Healthy Kids Canada), 2012. 'Is active play extinct?' The Active Healthy Kids Canada 2012: Report Card on Physical Activity for Children and Youth. Toronto: Active Healthy Kids Canada.

AHK Global Alliance, 2017. The global matrix 2.0 on physical activity for children and youth. Source (https://www.activehealthykids.org), accessed 16 November 2017.

Ahmed, S., 2006. Queer phenomenology. Durham, NC: Duke University Press.

Alexander S.A., Frohlich K.L., and Fusco C., 2014. Active play may be lots of fun, but it's certainly not frivolous': The emergence of active play as a health practice in Canadian public health. Sociology of Health and Illness, 36 (8), 1188-1204.

Alexander, S.A., Fusco, C., and Frohlich, K.L., 2015. 'You have to do 60 minutes of physical activity per day... I saw it on TV.': Children's play narratives in the context of the public health discourse of playing for health. Sociology of Health and Illness, 37 (2), 227-240.

Andrews, D., 2008. Kinesiology's inconvenient truth and the physical cultural studies imperative. Quest, 60, 45-62.

Armstrong, D., 2002. A new history of identity. Palgrave Macmillan: London.

Azguridienè, G. and Delkeskamp-Hayes, C., 2015. Public health care in Europe: Moral aspirations, ideological obsessions, and structural pitfalls in a postenlightenment culture, The Journal of Medicine and Philosophy, 40(2), 221-62.

Bennett, J., 2009. Vibrant matter: A political ecology of things. Durham (NC): Duke University Press.

Brady, G., Lowe, and Lauritzen, S.O., eds, 2015. Children, health and well-being: Policy debates and lived experience. Chichester: Wiley Blackwell.

Carson V., Ridgers N.D., Howard B.J., et al., 2013. Light-intensity physical activity and cardiometabolic biomarkers in US adolescents. PLoS One, 8 (8), e71417.

Carson V., Rinaldi R.L., Torrance B., et al., 2014. Vigorous physical activity and longitudinal associations with cardiometabolic risk factors in youth. International Journal of Obesity, 38 (1), 16-21. 
Cole, D. R., 2011. The actions of affect in deleuze: Others using language and the language that we make. Educational Philosophy and Theory, 43(6), 549-561. doi:10.1111/j.1469-5812.2009.00604.x

Cornell, D., 1992. The philosophy of the limit. New York: Routledge.

Crawford, R., 1990. Healthism and the medicalization of everyday life. International Journal of Health Services, 10, 365-88.

Dakgas, S. and Burrows, L., 2016. Families, Young People, Physical Activity and Health: Critical Perspectives. London: Routledge.

Damiano, D.L., 2006. Activity, activity, activity: Rethinking our physical therapy approach to cerebral palsy. Physical Therapy, 86 (11), 1534.

Darnell, S., 2014. Orientalism through sport: Towards a Said-ian analysis of imperialism and 'Sport for Development and Peace. Sport in Society, 17(8), 1000-1014.

De Landa, M., 1997. The machinic phyllum. Source: (http://v2.nl/archive/articles/themachinic-phylum), accessed 2 November 2017.

Deleuze, G., 1988. Spinoza: Practical philosophy. Trans. Robert Hurley. San Francisco: City Lights Books.

Deleuze, G., 1995. Negotiations: 1972-1990. New York: Columbia University Press.

Deleuze, G. and Guattari, F., 1983. Anti-Oedipus: Capitalism and schizophrenia . Minneapolis: University of Minnesota Press.

Deleuze, G., \& Guattari, F., 1994. What is philosophy? London: Verso.

Deleuze, G. and Guattari, F., 1987. A thousand plateaus: Capitalism and schizophrenia. Minneapolis: University of Minnesota Press.

Douglas, D., and Halas, J., 2013. The wages of whiteness: Confronting the nature of ivory tower racism and the implications for physical education. Sport, Education and Society, 18 (4), 453-474.

Douglas, S., Jivraj, S., and Lamble, S., 2011. Liabilities of queer anti-racist critique. Feminist Legal Studies, 19 (2), 107-118.

Evans, J., Rich, E., Davies, B., and Allwood, R., 2008. Education, disordered eating and obesity discourse: Fat fabrications. New York, NY: Routledge.

Fletcher, G.F., Ades, P.A., Kligfield, P., Arena, R., Balady, G.J., Bittner, V.A., Coke, L.A., Fleg, J.L., Forman, D.E., Gerber, T.C., Gulati, M., Madan, K., Rhodes, J., Thompson, P.D., Williams, M.A., 2013. Exercise standards for testing and 
training: A scientific statement from the American Heart Association. Circulation. doi: 10.1161/CIR.0b013e31829b5b44.

Foucault, M., 1977. Discipline and punish: The birth of the prison. Allen Lane: London. Foucault, M., 1990. The history of sexuality, Volume 1: An introduction. London: Penguin.

Frohlich, K.L., Alexander, S.A., and Fusco, C., 2013. All work and no play? The nascent discourse on play in health research. Social Theory and Health, 11 (1), $1-18$.

Galvin, R., 2002. Disturbing notions of chronic illness and individual responsibility: Towards a genealogy of morals, Health, 6 (2), 107-37.

Gard, M., and Wright, J., 2005. The obesity epidemic: Science, morality, and ideology. New York: Routledge.

Garo, I., 2008. Molecular revolutions: The paradox of politics in the work of Gilles Deleuze. In: I. Buchanan \& N. Thoburn, Deleuze and politics. Edinburgh: Edinburgh University Press, 54-73.

Giardina, M.D., 2017. (Post?) qualitative inquiry in sport, exercise, and health: notes on a methodologically contested present. Qualitative Research in Sport, Exercise and Health, 9 (2), 258-270.

Gibson, K., 2015a. A witness to fitness: Contextualizing processes in exercise physiology. Thesis (PhD). University of Toronto, Toronto ON.

Gibson, K., 2015b. Exercise as medicine, or the hinge, technique, and (in)activity. In: British Sociology Association Medical Sociology Group Annual Conference. York: University of York.

Gibson, K., 2016. When exercise becomes medicine. In: British Sociological Association South West Regional Medical Sociology Group and Centre for Health and Social Care Innovation Conference. Plymouth: University of Plymouth.

Greif, M., 2016. Against exercise. In: M. Greif, Against everything. New York: Random House, 3-15.

Hallward, P., 2006. Out of this world: Deleuze and the philosophy of creation. London: Verso.

Ingham, A., 1985. From public issue to private trouble: Wellbeing and the fiscal crisis of the state. Sociology of Sport Journal, 2, 43-55. 
Klein, N., 2007. The shock doctrine: The rise of disaster capitalism. London: Macmillan.

Kottke, F.J., 1965. Therapeutic exercise. In: F.H. Krusen, F.J. Kottke and P.M. Ellwood, eds. Handbook of physical medicine and rehabilitation. Philadelphia: W. B. Saunders Company, 365-406.

Krusen, F.H., 1942. Physical medicine: The employment of physical agents for diagnosis and therapy. Philadelphia: W.B. Saunders.

Lang, R., Koegel, L.K., Ashbaugh, K., Regester, A., Ence, W., and Smith, W., 2010. Physical exercise and individuals with autism spectrum disorders: A systematic review. Research in Autism Spectrum Disorders, 4, 565-576.

Lees, C., and Hopkins, J., 2013. Effect of aerobic exercise on cognition, academic achievement, and psychosocial function in children: a systematic review of randomized control trials. Preventing Chronic Disease, 10, E174.

Lupton, D., 2012. Medicine as culture: Illness, disease and the body in Western society. London: Sage.

McKenzie, S., 2013. Getting physical: The rise of fitness culture in America. Lawrence, Kansas: University Press of Kansas.

McKinlay, A., and Taylor, P., 2014. Foucault, governmentality, and organization: Inside the factory of the future. Routledge: New York.

Miller, P., and Rose, N., 2008. Governing the present: Administering economic, social and personal life. Cambridge, UK: Polity Press.

Mingardi, A., 2015. Healthcare and the slippery slope of state growth: Lessons from the past, Journal of Medicine and Philosophy, 40(2), 169-89.

Muñoz, J., 1999. Disidentifications: Queers of color and the performance of politics. Minneapolis: University of Minnesota.

Ontario Ministry of Education, 2015. The Ontario curriculum grades 1-8: Health and physical education. Available from: http://www.edu.gov.on.ca/eng/curriculum/elementary/health1to8.pdf [Accessed 4 February 2016].

ParticiPACtion, 2016. Make room for play. Available from: https://www.participaction.com/en-ca/programs/make-room-for-play [Accessed 2 February 2016]

Parsons, T., 1951. The social system. New York: Free Press. 
Powell, C., 2013. New Canadian Tire campaign bids us to go play. Available from: http://www.marketingmag.ca/brands/new-canadian-tire-campaign-bids-us-to-goplay-86007 [Accessed 4 February 2016].

Probyn, E., 2000. Sporting bodies: Dynamics of shame and pride. Body and Society, 6 (1), 13-28.

Pronger, B., 1995. Rendering the body: The implicit lessons of gross anatomy. Quest, 47, 427-446.

Pronger, B., 1999. Outta my endzone: Sport and the territorial anus. Journal of Sport and Social Issues, 23 (4), 373-389.

Pronger, B., 2002. Body fascism: Salvation in the technology of physical fitness. Toronto: University of Toronto Press.

Rail, G., 2012. The birth of the obesity clinic: Confessions of the flesh, biopedagogies and physical culture. Sociology of Sport Journal, 29 (2), 227-253.

Rich, E., 2011. Exploring the relationship between pedagogy and physical cultural studies: The case of the new health imperatives in schools. Sociology of Sport Journal, 28, 64-84.

Rose, N., 1999. Governing the soul: The shaping of the private self. 2nd ed. London: Routledge.

Rose, N., 2001. The politics of life itself. Theory, Culture and Society, 18 (6), 1-30.

Rose, N., 2007. Molecular biopolitics, somatic ethics and the spirit of biocapital. Social Theory and Health, 5 (1), 3-29.

Sontag, S., 1977. Illness as metaphor. London: Penguin.

Sothern, M., 2007. HIV + Bodyspace: AIDS and the queer politics of future negation in Aotearoa/New Zealand. In: K. Browne, J. Lim and G. Brown, eds, Geographies of sexualities: Theory, practice and politics. Aldershot: Ashgate, 181-194. Stoler, A.L., 1997. Race and the education of desire. Durham, NC: Duke University Press

Taguchi, H.L., and Palmer, A., 2014. Reading a Deleuzio-Guattarian cartography of young girls' 'School-related' ill-/wellbeing. Qualitative Inquiry, 20 (6), 764771.

Till, Chris., 2014. Exercise As Labour: Quantified Self and the Transformation of Exercise Into Labour. Societies 4(3). doi:10.3390/soc4030446.

Terlouw, T.J., 2007. The rise and fall of Zander-Institutes in the Netherlands around 1900. Medizin, Gesellschaft, Und Geschichte, 25, 91-124. 
Virilio, P., and Polizzotti, M., 1986. Speed and politics: An essay on dromology. New York: Columbia University Press.

Wheatley, E., 2005. Disciplining bodies at risk: Cardiac rehabilitation and the medicalization of fitness. Journal of Sport and Social Issues, 29, 198-221.

Williams, S. J., 1998. Health as moral performance: ritual, transgression and taboo. Health: An Interdisciplinary for the Social Study of Health, Illness and Medicine, 2(4), 435-457.

World Health Organization, 2017. Childhood overweight and obesity. Available from: http://www.who.int/dietphysicalactivity/childhood/en/ [Accessed 12 May 2017].

Wright, J., and Harwood, V., eds., 2009. Biopolitics and the obesity 'epidemic': Governing bodies. New York: Routledge.

Zweiniger-Bargielowska, I., 2006. Building a British superman: Physical culture in interwar Britain. Journal of Contemporary History, 41 (4), 595-610. 